$$
\begin{aligned}
& \text { SANO98-0178C } \\
& \text { SAND-98-0178C } \\
& \text { CONF-980620-- }
\end{aligned}
$$

\title{
Physical and Mechanical Properties of Degraded Waste Surrogate Material
}

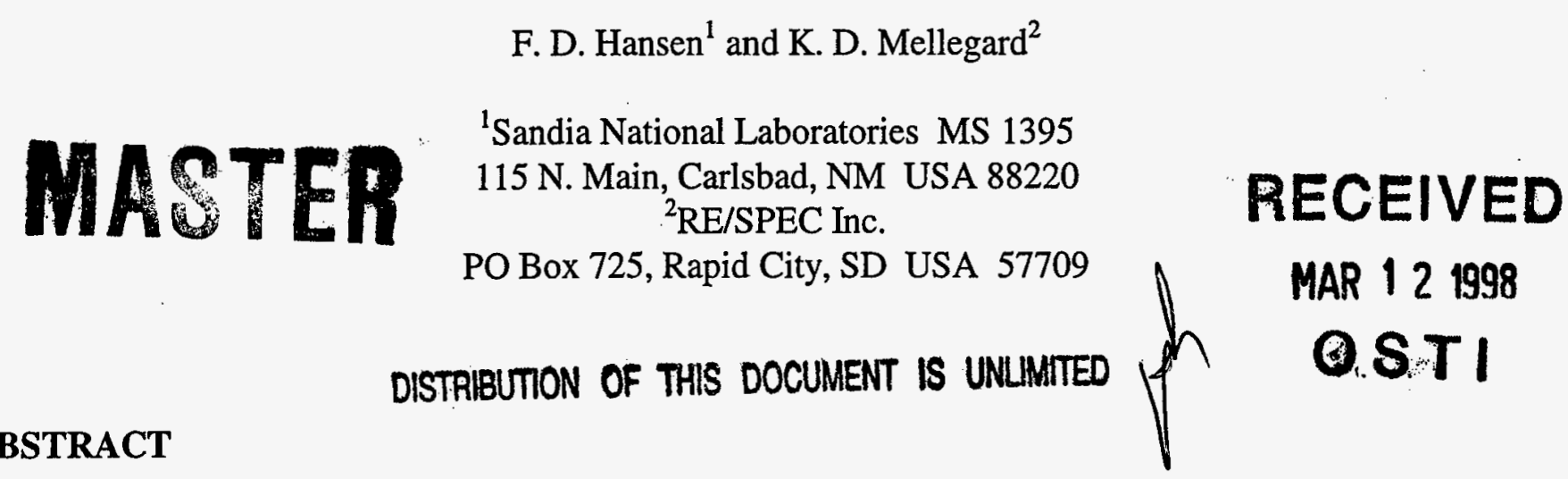

This paper discusses rock mechanics testing of surrogate materials to provide failure criteria for compacted, degraded nuclear waste. This daunting proposition was approached by first assembling all known parameters such as the initial waste inventory and rock mechanics response of the underground setting after the waste is stored. Conservative assumptions allowing for extensive degradation processes helped quantify the lowest possible strength conditions of the future state of the waste. In the larger conceptual setting, computations involve degraded waste behavior in transient pressure gradients as gas exits the waste horizon into a wellbore. Therefore, a defensible evaluation of tensile strength is paramount for successful analyses and intentionally provided maximal failed volumes. The very conservative approach assumes rampant degradation to define waste surrogate composition. Specimens prepared from derivative degradation product were consolidated into simple geometries for rock mechanics testing. Tensile strength thus derived helped convince a skeptical peer review panel that drilling into the Waste Isolation Pilot Plant (WIPP) would not likely expel appreciable solids via the drill string.

\section{KEYWORDS}

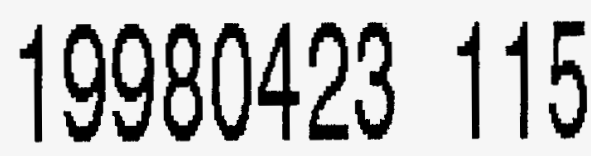

Surrogate material, failure mechanisms, tensile strength, nuclear waste, WIPP

\section{INTRODUCTION}

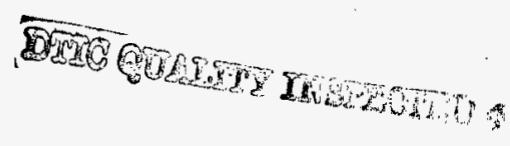

The certification process for opening the Waste Isolation Pilot Plant (WIPP) in the United States requires unprecedented analyses. One unique conceptual model examines and evaluates a future inadvertent drilling intrusion into the WIPP repository. The WIPP facility is located in southeastern New Mexico at a depth of $655 \mathrm{~m}$. The geologic setting comprises a great thickness of predominantly bedded halite adjacent to the repository horizon. This region of the United States contains significant quantities of natural resources, such as potash, gas and oil. Regulations for opening WIPP are written such that conventional drilling methods would be used to exploit natural resources, and these considerations are used in analyses of a hypothetical drilling intrusion.

A comprehensive description of the mechanistic model for a drilling intrusion into the WIPP (Hansen et al., 1997) provides detail, so only a cursory description of the drilling intrusion scenario will be given here. The 


\section{DISCLAMMER}

This report was prepared as an account of work sponsored by an agency of the United States Government. Neither the United States Government nor any agency thereof, nor any of their employees, makes any warranty, express or implied, or assumes any legal liability or responsibility for the accuracy, completeness, or usefulness of any information, apparatus, product, or process disclosed, or represents that its use would not infringe privately owned rights. Reference berein to any specific commercial product, process, or service by trade name, trademark, manufacturer, or otherwise does not necessarily constitute or imply its endorsement, recommendation, or favoring by the United States Government or any ageacy thereof. The views and opinions of authors expressed herein do not necessarily state or reflect those of the United States Government or.any agency thereof. 
basic conceptual model is based on the postulate that at some future date, there exists a remote possibility that a drilling operation may penetrate the site. If several other low-probability assumptions are invoked, it could be calculated that degraded waste material spalls into the drill string and is transported to the surface by expelling gas present in the repository. When taken together, these contributing assumptions allow calculation of theoretical solid releases, which remain between one and two orders of magnitude below the Environmental Protection Agency (EPA) limit (US DOE, 1996).

One of the great challenges pertaining to analysis of the possible "spall" phenomenon is characterization of the future state of the waste. Primary emphasis is devoted to quantifying waste tensile strength, although many other characteristics such as particle size, permeability, and heterogeneity would greatly influence potential spall release. Utilizing a known inventory of waste materials placed in the repository and conservatively allowing extensive degradation, recipes (mixtures) for surrogate products were determined. Representative surrogate recipes derived from corrosion of $50 \%$ and $100 \%$ of the iron-based inventory were fabricated and mechanically tested using standard laboratory procedures. The initial inventory contained in steel drums is used to define these extensively degraded byproducts. Subsurface processes leading to extreme degradation are based on conservative assumptions regarding brine availability, extensive microbial activity, corrosion, and the absence of cementation and salt encapsulation effects.

The total test matrix determined tensile strength, uniaxial and triaxial compressive strength, elastic constants, and brine permeability. Initial testing concentrated on the saturated state because it represents a conservatively low strength. Tensile strength was identified as the most important value for analyses under way at the time of the original work. Experience eventually led to focusing on a thick-walled hollow cylinder test for tensile strength. In summary, a rather complete evaluation of material properties for the selected well degraded waste surrogates was obtained. Tensile strength for all tests on $50 \%$ degraded surrogates averages $0.11 \mathrm{MPa}$ when saturated and $0.15 \mathrm{MPa}$ when dry. Unconfined compressive strength ranges from 0.32 to $1.4 \mathrm{MPa}$. Poisson's ratio averages 0.35 , Young's modulus is about $300 \mathrm{MPa}$, brine permeability is of the order of $4 \times 10^{-15} \mathrm{~m}^{2}$, and the angle of internal friction is approximately $45^{\circ}$. These results were employed in computations evaluating an inadvertent human intrusion at the WIPP.

\section{WASTE STATES}

Elements of these strength studies provide information on the range of potential forms of the waste (especially at the times and under the conditions at which spall events might occur) and are necessary to evaluate the resistance of degraded waste to spall release. In this section, salt creep, which greatly affects future states of the repository, is discussed first. Characteristics of the underground setting and mechanical waste compaction caused by room closure establish initial architecture of the repository horizon. Second, waste inventory and extreme degradation histories are used to develop combinations of surrogate materials for mechanical testing. Third, specimen preparation of the surrogate materials is discussed. Assumptions made here are thought to be very conservative and lead to ultra-conservative waste forms possessing very low strengths.

\section{Amount of Compaction}

Creep closure of the surrounding salt formation has been quantified through many in situ field-scale experiments, which validate the predictive capabilities of rock mechanics analyses. Mechanical response of waste drums as they are loaded by the creeping salt has been measured in the laboratory. Room closure and waste drum compression are relatively rapid processes. Over time, waste degradation and gas generation are postulated to occur. Characteristics of the underground setting can be followed logically to describe possible conditions that could exist at the time of drilling intrusion.

Plastic flow of salt is one of the primary reasons bedded salt is a preferred medium for permanent storage of nuclear waste. Salt creeps readily into underground openings, thereby compressing and entombing waste 
emplaced in the excavations. Predictions of repository rock mechanics response benefit from several fullscale room closure experiments spanning periods greater than a decade. Rock mechanics models for salt creep have been validated against long-term field measurements to the extent that confidence in room closure expectations exists in the technical community. In a recent report the National Research Council WIPP Committee notes that "as a result of an extensive rock mechanics research program, prediction of creep closure of repository excavations at WIPP is relatively straightforward" (NRC, 1996). On the basis of field measurements and validated constitutive models, predictions of room closure show rapid closure for the first 50 years after excavation, then appreciable slowing after attaining closure of $50 \%$ or more. Waste and other materials placed in the repository disposal rooms will be compacted to a thickness of less than $2 \mathrm{~m}$ before significant degradation occurs.

\section{Waste Corrosion/Degradation}

Conceptually, gas pressures in the WIPP are produced by corrosion of ferrous and nonferrous metals and by microbial degradation of cellulosic, plastic, and rubber waste constituents. A linkage was developed between waste inventory and physical and chemical processes to quantify appropriate surrogate materials for degraded waste experiments. At the outset, an ultra-conservative surrogate was developed rather than the expected average waste condition. Use of extremely degraded waste implies ample brine available and relatively small grain sizes. Corrosion of iron-bearing metals, aluminum, copper, and lead; the microbial-induced destruction of cellulosics, plastics, and rubber; and the breakdown of solidification media decreases the grain size of the initial waste constituents. The volume of metal-bearing solids in the repository will increase, however, as a result of corrosion reactions generating solid metal hydroxides, oxides, and carbonates. Representative surrogate materials are identified for the degraded waste residuals resulting from chemical reactions.

Development of surrogate waste materials began with definition of waste categories and their degradation products for cases of metal corrosion and microbial degradation of cellulosics, plastics, and rubber, consistent with Compliance Certification Application (CCA) calculations (US DOE, 1996). CCA calculations refer to a number of simulations completed as part of the Compliance Certification Application, which the Department of Energy submitted to the Environmental Protection Agency. It is likely that the extent of degradation of iron-bearing materials will be affected by their initial surface-to-volume ratio and the vertical position of the waste in the repository. In addition, calculated saturation of the repository depends on location, time following closure, and the values of sampled parameters. The existence of a gas phase may limit the corrosion of materials in upper portions of the repository, but downslope areas of the repository could possibly have higher brine saturation.

\section{Specimen Preparation}

Specimen preparation was limited to solid cylindrical shapes or thick-walled cylinders having a circular hole through the central axis. The process for preparing surrogate waste specimens required a number of sequential steps, including:

- preparation of raw materials

- weighing and mixing raw materials in appropriate proportions

- placement of the mixture in molds

- saturation of the mixture with brine

- drained consolidation using hydrostatic stress

- extraction of the consolidated specimen from the mold

- trimming or machining (if necessary)

- specimen drying (if applicable).

The surrogate waste comprised raw materials including iron, glass, cellulosics, rubber, plastic, solidification cements, soil, and WIPP salt. In general, each of these materials required some pretreatment to achieve particle sizes appropriate for the finished specimen. The iron constituent included simple iron (e.g., nails, 
rusted steel, scrap iron, etc.) and simulated decomposed iron $\left(\mathrm{Fe}_{2} \mathrm{O}_{3}\right.$ or goethite). The glass constituent comprised broken pane approximately 2 to $3 \mathrm{~mm}$ thick that passed a $9.5-\mathrm{mm}$ sieve. The cellulosics constituent included paper, cotton, sawdust, and peat. Sawdust and peat were used as received, while cotton was separated into thin strands by hand. Paper was cut into squares measuring approximately 6 to $8 \mathrm{~mm}$ on a side. The rubber constituent, which included O-rings, rubber bands, and rubber gloves, was cut to produce pieces having no dimension exceeding 6 to $8 \mathrm{~mm}$. Solidification cements, including hydrated concrete and gypsum, and crushed salt passed a $9.5-\mathrm{mm}$ sieve.

Mixtures were placed in a mold configured appropriately for the type of specimens to be produced: i.e., (1) solid cylinders with length-to-diameter ratios (L:D) of 2:2; (2) solid cylinders with L:D of 1:2 and a nominal diameter of $100 \mathrm{~mm}$; and (3) thick-walled hollow cylinders with an inside diameter of $30 \mathrm{~mm}$, an outside diameter of $100 \mathrm{~mm}$, and a length of $50 \mathrm{~mm}$. The mold was formed by securing a two-component jacketing system including a 1.6-mm-thick lead inner jacket and a flexible Viton outer jacket sealed to metal endcaps. Porous felt metal was placed in the interface between the endcap and the surrogate mixture. After the raw constituents had been molded, the specimen was saturated with WIPP brine by connecting the vent of the bottom endcap to a brine reservoir with a hydraulic surface located at an elevation above the vent in the top endcap. The brine was produced by saturating distilled water with finely ground salt recovered from the WIPP. Brine was permitted to flow from the reservoir through the specimen and out the top endcap. Saturation of the specimen was assumed when the brine effluent from the top vent ran freely with no entrapped air bubbles.

Saturated specimen/mold assemblies were placed inside the pressure vessel of a standard triaxial compression machine, and the annulus between the specimen mold and walls of the pressure vessel was filled with silicone oil. These specimens were consolidated (densified) under a hydrostatic stress of either 5 or $15 \mathrm{MPa}$. Initial tests consolidated the specimens to the approximate full lithostatic mean stress. However, the vast majority were consolidated to a lower stress of $5 \mathrm{MPa}$. Unsaturated specimens were prepared by slowly drying for varying lengths of time either in an oven at approximately $40^{\circ} \mathrm{C}$ or at room temperature and humidity. Actual water content was determined after testing by drying to constant mass in an oven at temperatures ranging from 40 to $95^{\circ} \mathrm{C}$. Water contents were expressed as a weight percentage of the dry specimen weight.

\section{TEST PROCEDURES}

Testing approaches include tensile strength measurements, uniaxial compression, and triaxial compression tests. Calibrations and quality assurance records are archived at Sandia National Laboratories.

\section{Tensile Strength}

Two alternative techniques were used: the Brazilian indirect method and hollow cylinders. These sample geometries were conducive to our specimen preparation apparatus. The Brazilian technique applies a compressive state to induce a tensile field, assuming an elastic solution. The indirect technique is probably satisfactory for partially dry (stiffer) surrogate waste; however, the saturated specimens were sufficiently ductile that tensile stress states predicted by elastic solutions might not be applicable. Therefore, an alternative test technique using hollow cylinders subjected to internal pressure was developed for most tensile strength values.

\section{Uniaxial Compression Tests}

Unconfined compressive strength calculates the stress at maximum load, corrected for instantaneous strain. Owing to the ductile nature of some surrogate waste specimens, load bearing capacity was not always apparent. In such cases, tests were terminated after large strain accumulation; and the corresponding load was used to calculate uniaxial strength. 


\section{Triaxial Compression Tests}

Confined quasi-static compressive strength tests determine peak axial stress difference, Young's modulus $(E)$, and Poisson's ratio $(v)$. Unload/reload cycles were performed to acquire data from which $E$ and $v$ could be calculated. In addition, two triaxial tests were simultaneously used for brine permeability measurements.

\section{RESULTS}

Test results will first summarize compressive strength, elastic properties, and permeability followed by tensile strengths. The analyses for which these tests were conducted emphasized tensile strength, and a more complete discussion will be accorded these tests. Four types of mechanical strength tests were performed: a uniaxial stress test, a Brazilian indirect tension test, a thick-walled cylinder test, and a triaxial compression test. The results of each test are presented with positive values indicating compression.

The ductile nature of the specimens during a triaxial compression test is illustrated in Figure 1, which plots axial stress difference versus axial and lateral strain for the triaxial compression test performed on specimen S14. The drained test was performed at room temperature using a constant confining pressure of $1 \mathrm{MPa}$. The load path incorporated two unload/reload cycles, which provided information for estimating the two elastic constants: Young's modulus and Poisson's ratio.

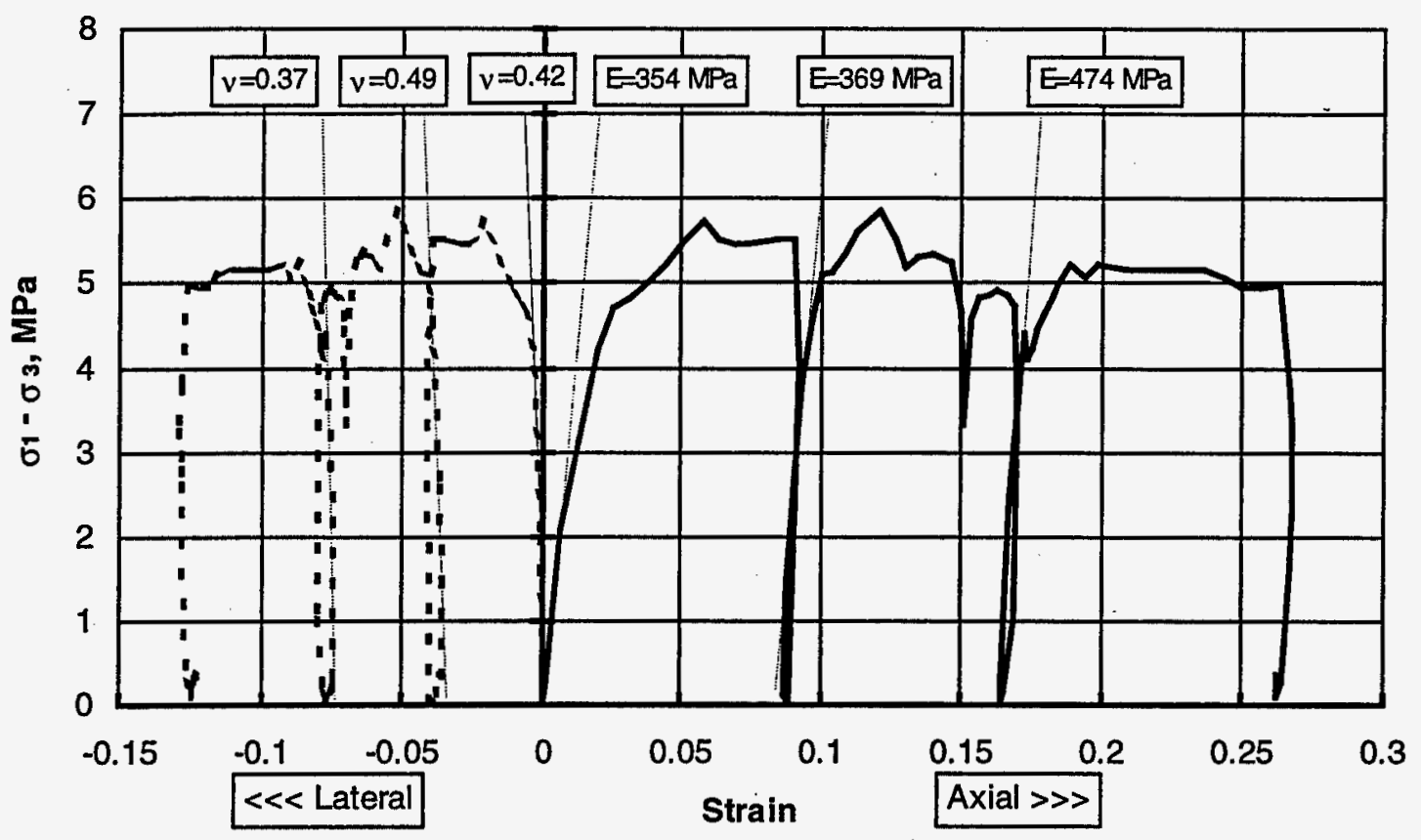

Figure 1: Triaxial compression test on Specimen S14

Young's modulus was calculated from the slope of the axial stress difference versus axial strain data during the ascending load portions of the curve. Poisson's ratio was calculated by first calculating a similar slope for the axial stress difference versus lateral strain data during the ascending load portions of the curve. The ratio of Young's modulus to this lateral strain slope represented Poisson's ratio. Three sets of elastic constant estimates were obtained in this fashion, and they are reported in Figure 1. The elastic constants for this test are also reported in Table 1, along with the elastic constants determined for triaxial tests on specimens $\mathrm{S} 6$ and $\mathrm{S} 23$. 
TABLE 1

ELASTIC CONSTANTS DETERMINED FROM TRIAXIAL COMPRESSION TESTS

\begin{tabular}{|l|c|c|c|c|}
\hline Specimen I.D. & Cycle & \multirow{2}{*}{$\begin{array}{c}\text { Confining } \\
\text { Pressure }\end{array}$} & \multicolumn{2}{|c|}{ Elastic Constants } \\
\cline { 4 - 5 } & & (MPa) & $E$ (MPa) & $v$ \\
\hline \multirow{3}{*}{ S6 } & Initial & & 21 & 0.35 \\
\hline \multirow{3}{*}{ S14 } & $1^{\text {st }}$ Reload & 0.05 & 72 & $0.09^{(\text {a) }}$ \\
\cline { 2 - 5 } & $2^{\text {nd }}$ Reload & & 73 & $0.07^{(\text {a) }}$ \\
\hline \multirow{3}{*}{ S23 } & Initial & & 354 & 0.42 \\
\cline { 2 - 5 } & $1^{\text {st }}$ Reload & 1.0 & 369 & 0.49 \\
\cline { 2 - 5 } & $2^{\text {nd }}$ Reload & & 474 & 0.37 \\
\cline { 2 - 5 } & Initial & & 76 & 0.40 \\
\cline { 2 - 5 } & $1^{\text {st }}$ Reload & 1.0 & 366 & 0.29 \\
\cline { 2 - 5 } & $2^{\text {nd }}$ Reload & & 220 & 0.36 \\
\cline { 2 - 5 } & $3^{\text {3d }}$ Reload & & 219 & 0.36 \\
\hline
\end{tabular}

(a) Test system control problems.

Two brine permeability tests were performed using a low confining pressure of $1 \mathrm{MPa}$ to seal the elastomer jacket against the specimen (after the protective lead jacket used during compaction had been removed). A low confining pressure was used to minimize the possibility of any additional change in specimen density during the permeability test. The brine permeant was driven with a $0.35 \mathrm{MPa}$ pressure at the specimen inlet while at the other end of the specimen a vented platen was connected to a burette to provide a measure of brine flow. The flow rate was linear, indicating a steady-state flow rate. Data were fitted to calculate the flow rate, which was then used to calculate a brine permeability. Two brine permeability tests yielded values of $5.3 \times 10^{-15} \mathrm{~m}^{2}$ and $2.1 \times 10^{-15} \mathrm{~m}^{2}$.

Seven unconfined compression tests were performed using the mixtures identified as $50 \%$ and $100 \%$ degraded waste. Five of those tests used specimens that were saturated with brine, and two of the tests used specimens that had initially been saturated with brine, but were dried before testing commenced. The strength of the wet specimens ranged from $0.32 \mathrm{MPa}$ to $1.4 \mathrm{MPa}$ and averaged $0.75 \mathrm{MPa}$. The two dry specimens displayed strengths of $1.0 \mathrm{MPa}$ and $1.3 \mathrm{MPa}$.

Thick-walled cylinder tests were performed to determine apparent tensile strength. These tests were performed by pressurizing the cylinders over their internal surface without applying any external pressure or axial stress. With this configuration, the maximum tensile stress experienced by the specimen occurs at the surface of the inner wall and may be calculated Eqn. 1 (Jaeger and Cook, 1976):

$$
T_{\max }=P_{\max } \frac{1+\left(R_{i} / R_{o}\right)^{2}}{1-\left(R_{i} / R_{o}\right)^{2}}
$$

where $T_{\max }$ is the maximum tensile stress, $P_{\max }$ is the maximum internal pressure applied, and $R_{\mathrm{i}}$ and $R_{\mathrm{o}}$ are the inner and outer radii of the cylinder, respectively. Thirty-six of these tests were performed on both wet and dry specimens characterized as $50 \%$ or $100 \%$ degraded waste material. The results are given in Table 2 .

The bulk of the tensile strength testing was performed using thick-walled specimens because that geometry was considered better suited to achieve uniform loading of the material. However, at the onset of the project, fourteen indirect tension tests were performed which displayed strength values ranging from $0.012 \mathrm{MPa}$ for a saturated specimen to $0.29 \mathrm{MPa}$ for a dry specimen and averaged $0.1 \mathrm{MPa}$ which is within the range of values seen in Table 2 . 
TABLE 2

TENSILE STRENGTHS DETERMDNED FROM THICK-WALLED CYLINDER TESTS

\begin{tabular}{|c|c|c|c|c|}
\hline $\begin{array}{c}\text { Specimen } \\
\text { ID } \\
\end{array}$ & $\begin{array}{c}\text { Waste } \\
\text { Surrogate Type }\end{array}$ & $\begin{array}{c}\text { Porosity } \\
(\%)\end{array}$ & $\begin{array}{c}\text { Saturation } \\
(\%)\end{array}$ & $\begin{array}{c}\text { Strength } \\
(\mathrm{MPa})\end{array}$ \\
\hline S19-1 & $50 \%$ & 20.2 & 100 & 0.122 \\
\hline S19-2 & $50 \%$ & 18.2 & 100 & 0.088 \\
\hline$S 21-1$ & $50 \%$ & 23.6 & 100 & 0.112 \\
\hline S21-2 & $50 \%$ & 19.7 & 100 & 0.129 \\
\hline S22-1 & $50 \%$ & 23.0 & 100 & 0.070 \\
\hline S22-2 & $50 \%$ & 20.5 & 100 & 0.120 \\
\hline S35-1 & $50 \%$ & 19.1 & 39.5 & 0.121 \\
\hline S35-2 & $50 \%$ & 20.8 & 38.7 & 0.140 \\
\hline S36-1 & $50 \%$ & 22.8 & 38.0 & 0.117 \\
\hline S36-2 & $50 \%$ & 25.3 & 41.2 & 0.126 \\
\hline S37-1 & $50 \%$ & 19.1 & 73.3 & 0.099 \\
\hline S37-2 & $50 \%$ & 17.1 & 67.1 & 0.108 \\
\hline S38-1 & $50 \%$ & 16.2 & 64.6 & 0.099 \\
\hline S38-2 & $50 \%$ & 16.0 & 720 & 0.091 \\
\hline S39-1 & $50 \%$ & 16.9 & 0 & 0.131 \\
\hline S39-2 & $50 \%$ & 19.3 & 0 & 0.122 \\
\hline S40-1 & $50 \%$ & 16.4 & 0 & 0.129 \\
\hline S40-2 & $50 \%$ & 16.3 & 0 & 0.146 \\
\hline S41-1 & $50 \%$ & 14.7 & 0 & 0.138 \\
\hline S41-2 & $50 \%$ & 14.5 & 0 & 0.122 \\
\hline S42-1 & $50 \%$ & 14.8 & 0 & 0.170 \\
\hline S42-2 & $50 \%$ & 15.4 & 0 & 0.138 \\
\hline S43-1 & $50 \%$ & 18.6 & 11.9 & 0.122 \\
\hline S43-2 & $50 \%$ & 16.7 & 8.90 & 0.122 \\
\hline S44-1 & $50 \%$ & 18.1 & 12.1 & 0.139 \\
\hline$S 44-2$ & $50 \%$ & 17.0 & 8.70 & 0.114 \\
\hline S45-1 & $50 \%$ & 13.8 & 0 & 0.166 \\
\hline$S 45-2$ & $50 \%$ & 13.8 & 0 & 0.175 \\
\hline$S 46-1$ & $50 \%$ & 15.1 & 0 & 0.131 \\
\hline S46-2 & $50 \%$ & 14.8 & 0 & 0.131 \\
\hline S49-1 & $100 \%$ & - & 0 & 0.165 \\
\hline S49-2 & $100 \%$ & - & 0 & 0.124 \\
\hline S50-1 & $100 \%$ & - & 0 & 0.132 \\
\hline S50-2 & $100 \%$ & - & 0 & 0.147 \\
\hline S52-1 & $100 \%$ & - & 100 & 0.050 \\
\hline S52-2 & $100 \%$ & & 100 & 0.049 \\
\hline
\end{tabular}

The data in Table 2 are shown graphically in Figure 2 which plots tensile strengths versus the level of specimen saturation at the time of testing. Figure 2 data indicate that the more highly saturated material is weaker than the dry material. Moreover, the effect that saturation has on the strength of the material is greater than the effect of changing the material constituents from a $50 \%$ degraded surrogate to a $100 \%$ degraded surrogate. 


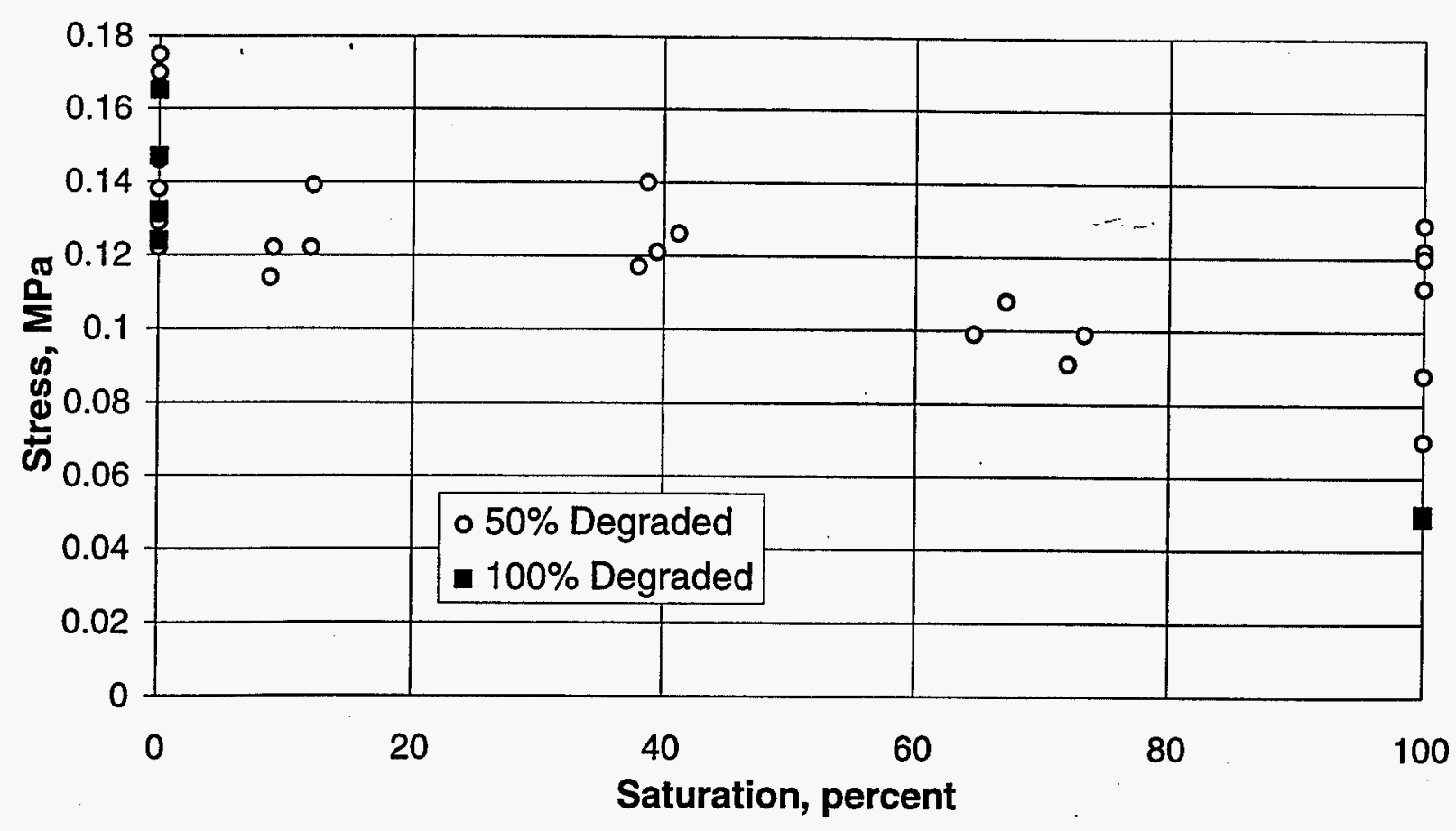

Figure 2: Tensile stress as a function of saturation

\section{DISCUSSION}

Evaluation of hypothetical events, such as a drilling intrusion into the WIPP site at some time far into the future, presents quite a challenge. Regardless of the sophistication of the conceptual model itself, in terms of wellbore dynamics or transient gas blowdown, characteristics of the intruded horizon-the future state of the waste-will control delivery of solid material in a spall event. We began these studies of degraded surrogate materials deliberately to determine the most conservative strength values.

Test specimens were fabricated using fractions of surrogate materials appropriate for an extremely degraded waste inventory. Initial dimensions of compression samples were approximately $100 \mathrm{~mm}$ in diameter and $200 \mathrm{~mm}$ in length. Compaction was applied hydrostatically in a drained, saturated state. Brine permeability, failure strengths, and elastic constants were measured. Tensile strength testing accomplished using hollow cylinders indicated that, as expected, saturated surrogate samples are fairly weak and ductile. Tensile strength of saturated samples ranges from 0.05 to $0.13 \mathrm{MPa}$. Unconfined compressive strength of saturated samples ranges from 0.32 to $1.4 \mathrm{MPa}$. Poisson's ratio averages about 0.35 , Young's modulus is approximately $300 \mathrm{MPa}$, permeability is of the order of $4 \times 10^{-15} \mathrm{~m}^{2}$. Based on the few tests available, surrogate waste material is highly pressure sensitive $\left(\phi \approx 45^{\circ}\right)$.

Experimental variations allow evaluation of saturated, dry, and partially dry states for consolidation pressure effects between 5 and $15 \mathrm{MPa}$ and for recipe variations. Initially, specimens were consolidated at $15 \mathrm{MPa}$, as that represented a nominal lithostatic pressure at the WIPP. To be conservative with regard to the pressure the waste actually experiences, a lower pressure of $5 \mathrm{MPa}$ was used after the first several tests. Four saturated, unconfined compression tests were conducted on identical recipes. Three tests prepared at $15 \mathrm{MPa}$ consolidation pressure provided unconfined strengths of $1.6,0.32$, and $0.70 \mathrm{MPa}$. The fourth test prepared at $5 \mathrm{MPa}$ consolidation failed at an intermediate strength of $0.65 \mathrm{MPa}$. On this basis, no strength enhancement was found for consolidation to lithostatic pressures; however, further specimen preparation consolidation used a pressure of $5 \mathrm{MPa}$.

Tensile strength is thought to be the most significant with respect to failure and possible transport during a spall event. Therefore, several variations of test parameters were used in determining saturated and dry tensile strengths of surrogate recipes. Referring to Table 2, saturated tensile strength for the $50 \%$ degraded 
čase averages $0.11 \mathrm{MPa}(15.5 \mathrm{psi})$ and ranges from 0.07 to $0.13 \mathrm{MPa}$. Saturated tensile strength of the $100 \%$ degraded case averages $0.05 \mathrm{MPa}(7.3 \mathrm{psi})$ and displays nearly identical results for two tests. It appears that in the saturated state, the surrogates representing 50\% degraded waste are stronger than those representing $100 \%$ degraded waste, although the database of $100 \%$ degraded results is small. Twelve dry tests on the $50 \%$ degraded surrogate yield an average tensile strength of $0.146 \mathrm{MPa}(21.2 \mathrm{psi})$. By comparison, four dry tests on the $100 \%$ degraded surrogate average $0.142 \mathrm{MPa}$ (20.6 psi). Precipitate strength develops as degraded waste dries because $\mathrm{NaCl}$ crystallites would precipitate on grain boundaries. This is a likely physical process of strength increases noted for dry surrogate specimens. Drying increases tensile strength by about a factor of two compared to the saturated condition. Significant increase above saturated strength would be appropriate for calculations of spall at high pressures because of the concomitant dry condition.

\section{CONCLUDING REMARKS}

This work establishes strength and deformational characteristics of surrogate material representing an extremely conservative future state of the waste. The expected state of the waste at times when spall is most likely to occur comprises compacted drums of waste, encrusted along contact boundaries with minor degradation product. When expected states of the waste are considered, the most likely conditions suggest that spalling would not be possible from the WIPP waste rooms. However, the expected states of the WIPP are not the most relevant to the hypothetical spall event. This testing was conducted to quantify extreme conditions that capture the "low end" of possible mechanical strength created as a result of extensive degradation.

As investigations continue, a more representative state of the waste comprising crushed, compacted, cemented, partially degraded 55 gallon drums will be considered. In a "dry or nearly dry" repository as noted by the NRC report (1996), degradation will be minimal. As a result, the blocky, heterogeneous architecture of compacted waste inventory would not be conducive to gas-driven transport under any circumstances.

\section{REFERENCES}

Hansen, F.D., Knowles M.K., Thompson T.W., Gross M.B., McLennan J.D., Schatz J.F. (1997). Description and Evaluation of a Mechanistically Based Conceptual Model for Spall, SAND97-1369. Sandia National Laboratories, Albuquerque, NM.

Jaeger, J.C., Cook, N.G.W. (1976). Fundamentals of Rock Mechanics, Second Edition, John Wiley and Sons, New York, NY.

NRC (National Research Council). (1996). The Waste Isolation Pilot Plant: A Potential Solution for the Disposal of Transuranic Waste. Committee on the Waste Isolation Pilot Plant, Board on Radioactive Waste Management, Commission On Geosciences, Environment and Resources, National Research Council. National Academy Press, Washington, DC.

US DOE (Department of Energy). (1996). Title 40 CFR Part 191 Compliance Certification for the Waste Isolation Pilot Plant. DOE/CAO-1996-2184. Carlsbad, NM: United States Department of Energy, Waste Isolation Pilot Plant, Carlsbad Area Office.

\section{ACKNOWLEDGMENT}

Sandia is a multiprogram laboratory operated by Sandia Corporation, a Lockheed Martin Company, for the United States Department of Energy under Contract DE-ACO4-94AL85000 


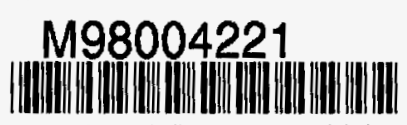

Report Number (14) $5 A N D--98-0178 \mathrm{C}$
CONF-980620--

Publ. Date (11) $\frac{199803}{\text { Sponsor Code (18) }} \frac{\text { DOE/EM, XF }}{\text { UC-2000, DOE/ER }}$
UC Category (19) 